\title{
Facile Synthesis of Nano-Si Modified Graphite Composite as Anode Material for Lithium Ion Batteries
}

\author{
Hou Jiao ${ }^{1}$, Gong Bo-Lin ${ }^{1, *}$, Hou Chun-Ping ${ }^{2,3}$,Wang Bei-Ping ${ }^{2}$, Yang Dan ${ }^{3}$,Wang Xing-Wei ${ }^{3}$ \\ ${ }^{1}$ College of Chemistry and Chemical Engineering, North Minzu University, Yinchuan Ningxia, \\ 750021, P.R. China \\ ${ }^{2}$ College of Materials Science and Engineering, North Minzu University, Yinchuan Ningxia, 750021, \\ P.R. China \\ ${ }^{3}$ Ningxia BOLT Technologies Co., Ltd., Yinchuan Ningxia, 750002, P.R. China \\ *E-mail: gongbolin@163.com
}

doi: $10.20964 / 2019.04 .22$

Received: 7 December 2018 / Accepted: 10 January 2019 / Published: 10 March 2019

\begin{abstract}
We used a liquid-phase method to prepare a novel high capacity nano-Si modified graphite composite electrode material for lithium ion batteries. In this method, nano-Si powder was deposited onto the surface of natural spherical graphite using wet ball milling. CMC in solution was used as a binder between nano-Si and graphite and acted as a $\mathrm{C}$ coating in the sintering process. The acquired nano-Si modified graphite composite was investigated using X-ray diffraction (XRD), scanning electron microscopy (SEM). Electrochemical tests showed that the $\mathrm{C}$ coated nano-Si modified graphite composite had good electrochemical properties, such as high specific capacity, good rate capability and cycling performance and therefore was suitable for use in power or energy storage batteries. The $5 \mathrm{wt} \%$ nano-Si sample had a high specific capacity of $464.8 \mathrm{mAh} \mathrm{g}^{-1}$ at $0.1 \mathrm{C}$ rate, which was approximately $87.37 \%$ of the theoretical specific capacity $\left(\sim 532 \mathrm{mAh} \mathrm{g}^{-1}\right)$.
\end{abstract}

Keywords: Nano-Si powder; Natural graphite; Composite; Liquid-phase; Carbon coating

\section{$\underline{\text { FULL TEXT }}$}

(C) 2019 The Authors. Published by ESG (www.electrochemsci.org). This article is an open access article distributed under the terms and conditions of the Creative Commons Attribution license (http://creativecommons.org/licenses/by/4.0/). 